\title{
Body mass index as a measure of body fatness: age- and sex- specific prediction formulas
}

\author{
BY PAUL DEURENBERG, JAN A. WESTSTRATE* AND JAAP C. SEIDELL \\ Department of Human Nutrition, Agricultural University Wageningen, Bomenweg 2, 6703 HD, \\ Wageningen, The Netherlands
}

(Received 26 March 1990 - Accepted 9 October 1990)

In 1229 subjects, 521 males and 708 females, with a wide range in body mass index (BMI; $13 \cdot 9-40 \cdot 9 \mathrm{~kg} / \mathrm{m}^{2}$ ), and an age range of $7-83$ years, body composition was determined by densitometry and anthropometry. The relationship between densitometrically-determined body fat percentage (BF\%) and BMI, taking age and sex (males $=1$, females $=0$ ) into account, was analysed. For children aged 15 years and younger, the relationship differed from that in adults, due to the height-related increase in BMI in children. In children the $\mathrm{BF} \%$ could be predicted by the formula $B F \%=1.51 \times \mathrm{BMI}-$ $0.70 \times$ age $-3.6 \times \operatorname{sex}+1.4\left(R^{2} 0.38\right.$, SE of estimate (SEE) $\left.4.4 \% \mathrm{BF} \%\right)$. In adults the prediction formula was: $\mathrm{BF} \%=1.20 \times \mathrm{BMI}+0.23 \times$ age $-10.8 \times \operatorname{sex}-5.4\left(R^{2} 0.79\right.$, SEE $\left.=4.1 \% \mathrm{BF} \%\right)$. Internal and external cross-validation of the prediction formulas showed that they gave valid estimates of body fat in males and females at all ages. In obese subjects however, the prediction formulas slightly overestimated the $\mathrm{BF} \%$. The prediction error is comparable to the prediction error obtained with other methods of estimating $\mathrm{BF} \%$, such as skinfold thickness measurements or bioelectrical impedance.

Body composition: Body mass index: Obesity

Numerous methods are available to assess body composition, all with their own advantages and limitations (Lukaski, 1987). Only a few methods are suitable in epidemiological studies or clinical practice, because of their technical simplicity, their low costs, or the fact that they are not time consuming. These methods include the bioelectrical impedance technique (Lukaski et al. 1985, 1986; Lukaski, 1987; Segal et al. 1988), infra-red interactance (Conway et al. 1984; Elia et al. 1990) and anthropometry such as skinfold thickness measurements (Durnin \& Womersley, 1974; Pollock et al. 1975; Jackson \& Pollock, 1978; Slaughter et al. 1988; Deurenberg et al. 1990) or weight-height indices (Khosla \& Lowe, 1967; Keys et al. 1972; Womersley \& Durnin, 1977; Norgan \& Ferro-Luzzi, 1982; Garrow \& Webster, 1985).

For the assessment of body fat percentage $(\mathrm{BF} \%)$ in epidemiological studies, a weight-height index is the most simple method. A minimum of (inexpensive) equipment is needed, i.e. only a balance and a stadiometer or microtoise, and the errors in measurement due to intra- or inter-observer variation are small. From the several weight-height indices the body mass index (BMI) or Quetelet's index, defined as body-weight/height ${ }^{2}$ (Quetelet, 1869), seems to be the most appropriate, because its correlation with $\mathrm{BF} \%$ is high, and its correlation with body height is low (Khosla \& Lowe, 1967; Keys et al. 1972; Womersley \& Durnin, 1977; Garrow \& Webster, 1985). Due to differences in body composition between males and females, and the age-related increase in body fat mass and the decrease in fat-free mass (Forbes, 1987), the relationship between $\mathrm{BF} \%$ and $\mathrm{BMI}$ will be sex- and age-dependent.

The aim of the present study was to determine the relationship between densitometrically-

* Present address: Unilever Research Laboratory, Olivier van Noortlaan 120, 3133 AT Vlaardingen, The Netherlands. 
determined $\mathrm{BF} \%$ and $\mathrm{BMI}$, taking age and sex into account, and to cross-validate the developed prediction formulas.

\section{SUBJECTS AND METHODS}

Data from 1229 healthy subjects, 521 males and 708 females, were used in the present study. All subjects participated as volunteers in studies on body composition or energy metabolism of which the protocols were approved by the Ethical Committee of the Department of Human Nutrition. The subjects showed a wide age range (7-83 years) and ranged in $\mathrm{BF} \%$ from 5 to 50 . The $\mathrm{BMI}$ ranged from 13.9 to $40.9 \mathrm{~kg} / \mathrm{m}^{2}$. The total group of subjects was randomly divided into two groups: group A, and a cross-validation group B. To facilitate the preliminary crude analysis on the age dependency of the relation between $\mathrm{BF} \%$ and $\mathrm{BMI}$, the population was divided into nine age groups: group 1, 7-10 years; group 2, 11-15 years; group 3, 16-20 years; group 4, 21-25 years; group 5, 26-35 years; group 6, 36-45 years; group 7, 46-55 years; group 8, 56-65 years; group 9, $\geqslant 66$ years.

Body-weight was measured to the nearest $0.05 \mathrm{~kg}$ with a digital scale (Berkel ED60-T, Rotterdam, The Netherlands). Body height was measured by means of a microtoise to the nearest $0.001 \mathrm{~m}$. Body density was determined in duplicate by underwater weighing (to the nearest $0.05 \mathrm{~kg}$, Sartorius 3826MP 81, Göttingen, Germany) with simultaneous determination of the lung volume by a helium dilution technique (Spiro-Junior, Jaeger GmBH, Würtzburg, Germany). In subjects aged 18 years and younger, BF\% was calculated with an age-specific formula (Weststrate \& Deurenberg, 1989; Deurenberg et al. 1990). In subjects older than 18 years, BF\% was calculated from body density using Siri's (1961) equation with corrections for age and level of body fatness (Deurenberg et al. 1989 b, c). Multiple stepwise linear regression (Kleinbaum \& Kupper, 1978) was used to analyse the relationship between $\mathrm{BF} \%$ as dependent variable and $\mathrm{BMI}$, age and sex as independent variables, using the Statistical Package of Social Sciences/PC-1988-program. Prediction formulas were developed for a population of children (aged $\leqslant 15$ years) and a population of adults (aged $\geqslant 16$ years).

Some physical characteristics of the subjects in the validation and cross-validation group are given in Table 2 (p. 107). ANOVA was used to test for differences between groups. Differences between measured and predicted parameters were tested for significance by the paired two-sided Student's $t$ test. All results are expressed as means with their standard errors.

\section{RESULTS}

Table 1 shows for males and females in each age group the correlation coefficient between $\mathrm{BMI}$ and body height and $\mathrm{BF} \%$. In the two lower age groups, that is until the age of 16 years, BMI and body height were positively $(P<0.001)$ correlated, whereas in the older age groups the correlation between BMI and height was not significant or even negative. For the total adult male and adult female groups the correlation of BMI with body height was -0.30 and $-0 \cdot 19$ respectively $(P<0 \cdot 01)$. BF\% was also negatively correlated with body height (correlation coefficient -0.43 and -0.23 in males and females respectively, $P<$ 0.001 ). After correction for the effect of $\mathrm{BF} \%$ the partial correlation of BMI with body height in both males and females was 0.02 , which is not significantly different from zero. In children $\mathrm{BF} \%$ and body height were not correlated.

The correlation of $\mathrm{BMI}$ with $\mathrm{BF} \%$ was generally higher in the adult groups. In the total group of children the correlation between $\mathrm{BMI}$ and $\mathrm{BF} \%$ was 0.43 and $0.53(P<0.001)$, whereas in the adult male and female groups the correlations were 0.75 and 0.76 respectively $(P<0 \cdot 001)$. Therefore subsequent analyses were performed in two age 
Table 1. Correlation coefficient of body mass index and body height and body fat \% in different age groups

\begin{tabular}{|c|c|c|c|c|c|c|c|c|c|}
\hline Age (years)... & $7-10$ & $11-15$ & $16-20$ & $21-25$ & $26-35$ & $36-45$ & $46-55$ & $56-65$ & $\geqslant 66$ \\
\hline $\begin{array}{l}\text { Males }(n) \\
\text { Body height } \\
\text { Body fat } \%\end{array}$ & $\begin{array}{l}56 \\
0.55^{*} \\
0 \cdot 59^{*}\end{array}$ & $\begin{array}{l}177 \\
0.50^{*} \\
0.44^{*}\end{array}$ & $\begin{array}{l}50 \\
0.09 \\
0 \cdot 39^{*}\end{array}$ & $\begin{array}{l}101 \\
-0 \cdot 28^{*} \\
0 \cdot 47^{*}\end{array}$ & $\begin{array}{l}25 \\
-0.47^{*} \\
0.92^{*}\end{array}$ & $\begin{array}{l}45 \\
-0 \cdot 18 \\
0.74^{*}\end{array}$ & $\begin{array}{l}23 \\
0.09 \\
0 \cdot 80^{*}\end{array}$ & $\begin{array}{l}15 \\
-0.35 \\
0.72 *\end{array}$ & $\begin{array}{l}29 \\
-0.01 \\
0.37\end{array}$ \\
\hline $\begin{array}{l}\text { Females }(n) \\
\text { Body height } \\
\text { Body fat } \%\end{array}$ & $\begin{array}{l}83 \\
0.44^{*} \\
0.63^{*}\end{array}$ & $\begin{array}{l}164 \\
0.38^{*} \\
0.65^{*}\end{array}$ & $\begin{array}{l}120 \\
-0.07 \\
0.55^{*}\end{array}$ & $\begin{array}{l}203 \\
0 \cdot 06 \\
0 \cdot 51^{*}\end{array}$ & $\begin{array}{l}24 \\
0.08 \\
0.89^{*}\end{array}$ & $\begin{array}{l}50 \\
-0 \cdot 15 \\
0.81^{*}\end{array}$ & $\begin{array}{l}21 \\
0 \cdot 33 \\
0 \cdot 75^{*}\end{array}$ & $\begin{array}{l}22 \\
-0 \cdot 20 \\
0 \cdot 50^{*}\end{array}$ & $\begin{array}{l}21 \\
-0.22 \\
0.51\end{array}$ \\
\hline
\end{tabular}

Table 2. Physical characteristics of the two populations (groups $A$ and $B$ ) of children and adults

(Means with their standard errors)

\begin{tabular}{|c|c|c|c|c|c|c|c|c|}
\hline & \multicolumn{4}{|c|}{ Children } & \multicolumn{4}{|c|}{ Adults } \\
\hline & \multicolumn{2}{|c|}{ Group A } & \multicolumn{2}{|c|}{ Group B } & \multicolumn{2}{|c|}{ Group A } & \multicolumn{2}{|c|}{ Group B } \\
\hline & Mean & $\mathrm{SE}$ & Mean & SE & Mean & SE & Mean & SE \\
\hline Male/female & \multicolumn{2}{|c|}{$12 \mathrm{l} / 132$} & \multicolumn{2}{|c|}{$112 / 115$} & \multicolumn{2}{|c|}{$140 / 216$} & \multicolumn{2}{|c|}{$148 / 245$} \\
\hline Body-wt (kg) & $41 \cdot 3$ & $0 \cdot 7$ & $41 \cdot 6$ & $0 \cdot 8$ & $69 \cdot 4$ & $0 \cdot 7$ & $70 \cdot 2$ & 0.6 \\
\hline Body height (m) & $1 \cdot 517$ & 0.009 & $1 \cdot 518$ & 0.009 & $1 \cdot 740$ & 0.005 & 1.736 & $0 \cdot 005$ \\
\hline $\begin{array}{l}\text { Body mass index } \\
\left(\mathrm{kg} / \mathrm{m}^{2}\right)\end{array}$ & $17 \cdot 6$ & $0 \cdot 1$ & $17 \cdot 7$ & $0 \cdot 1$ & $22 \cdot 9$ & $0 \cdot 2$ & $23 \cdot 2$ & 0.2 \\
\hline Body density $(\mathrm{kg} / \mathrm{l})$ & $1 \cdot 047$ & $0 \cdot 001$ & $1 \cdot 048$ & 0.001 & $1 \cdot 042$ & 0.001 & 1.039 & 0.001 \\
\hline Body fat $(\%)$ & $18 \cdot 4$ & $0 \cdot 4$ & $18 \cdot 0$ & 0.4 & $24 \cdot 7$ & 0.5 & $25 \cdot 7$ & 0.4 \\
\hline
\end{tabular}

Table 3. Regression of body fat percentage (BF\%) as dependent variable, and body mass index (BMI), age and sex as independent variables in the populations of children (age $\leqslant 15$ years)

(Means with their standard errors)

\begin{tabular}{|c|c|c|c|c|c|c|c|c|c|c|c|}
\hline \multirow[b]{3}{*}{ Group $n$} & \multicolumn{8}{|c|}{ Regression coefficients } & & & \\
\hline & \multicolumn{2}{|c|}{ BMI } & \multicolumn{2}{|c|}{ Sex* } & \multicolumn{2}{|c|}{ Age } & \multicolumn{2}{|c|}{ Intercept } & \multicolumn{2}{|c|}{ SEE } & \multirow[b]{2}{*}{$R^{2}$} \\
\hline & Mean & SE & Mean & $\mathrm{SE}$ & Mean & $\mathrm{SE}$ & Mean & $\mathbf{S E}$ & $\mathrm{BF} \%$ & $\mathrm{CV} \%$ & \\
\hline A 253 & $\begin{array}{l}+1 \cdot 32 \\
+1 \cdot 33 \\
+1.72\end{array}$ & $\begin{array}{l}0 \cdot 14 \\
0 \cdot 13 \\
0 \cdot 15\end{array}$ & $\begin{array}{l}-3 \cdot \overline{-} \\
-3 \cdot 5\end{array}$ & $\begin{array}{l}0.6 \\
0.5\end{array}$ & -0.77 & 0.15 & $\begin{array}{l}-4 \cdot 9 \\
-3 \cdot 2 \\
-1 \cdot 1\end{array}$ & $\begin{array}{l}2 \cdot 6 \\
2 \cdot 4 \\
2 \cdot 3\end{array}$ & $\begin{array}{l}4 \cdot 8 \\
4 \cdot 4 \\
4 \cdot 2\end{array}$ & $\begin{array}{l}26 \\
24 \\
23\end{array}$ & $\begin{array}{l}0.25 \\
0 \cdot 36 \\
0.42\end{array}$ \\
\hline B 227 & $\begin{array}{l}+1 \cdot 12 \\
+1.03 \\
+1.32\end{array}$ & $\begin{array}{l}0 \cdot 15 \\
0 \cdot 14 \\
0 \cdot 16\end{array}$ & $\begin{array}{l}-3 \cdot 9 \\
-3 \cdot 7\end{array}$ & $\begin{array}{l}0.6 \\
0.6\end{array}$ & -0.62 & 0.17 & $\begin{array}{l}-1.9 \\
+1.6 \\
+3.8\end{array}$ & $\begin{array}{l}2 \cdot 7 \\
2 \cdot 5 \\
2 \cdot 6\end{array}$ & $\begin{array}{l}5 \cdot 0 \\
4 \cdot 7 \\
4 \cdot 6\end{array}$ & $\begin{array}{l}28 \\
26 \\
25\end{array}$ & $\begin{array}{l}0.20 \\
0.32 \\
0.35\end{array}$ \\
\hline$A+B 480$ & $\begin{array}{l}+1 \cdot 22 \\
+1.18 \\
+1.51\end{array}$ & $\begin{array}{l}0 \cdot 10 \\
0-09 \\
0 \cdot 11\end{array}$ & $\begin{array}{r}-\overline{-} \\
-3.8 \\
-3.6\end{array}$ & $\begin{array}{l}0.4 \\
0.4\end{array}$ & -0.70 & 0.12 & $\begin{array}{l}-3 \cdot 3 \\
-0.7 \\
+1.4\end{array}$ & $\begin{array}{l}1 \cdot 9 \\
1 \cdot 7 \\
1 \cdot 7\end{array}$ & $\begin{array}{l}4 \cdot 9 \\
4 \cdot 6 \\
4 \cdot 4\end{array}$ & $\begin{array}{l}27 \\
25 \\
24\end{array}$ & $\begin{array}{l}0 \cdot 22 \\
0 \cdot 34 \\
0 \cdot 38\end{array}$ \\
\hline
\end{tabular}

SEE, standard error of estimate, CV\%, coefficient of variation; $R^{2}$, explained variance.

* Sex: males $=1$, females $=0$. 
Table 4. Observed body fat percentage ( $B F \%$ ) and difference with predicted $B F \%$ in the two populations of children and the two combined populations of children*

(Means with their standard errors)

\begin{tabular}{|c|c|c|c|c|c|c|c|c|}
\hline \multirow[b]{3}{*}{ Group $n$} & & & \multicolumn{6}{|c|}{$\begin{array}{l}\text { Difference between predicted and observed } \mathrm{BF} \% \\
\text { when predicted with equation from population } \dagger\end{array}$} \\
\hline & \multicolumn{2}{|c|}{ Observed $\mathrm{BF} \%$} & \multicolumn{2}{|c|}{ A } & \multicolumn{2}{|c|}{ B } & \multicolumn{2}{|c|}{$A+B$} \\
\hline & Mean & $\mathrm{SE}$ & Mean & $\mathrm{SE}$ & Mean & $\mathrm{SE}$ & Mean & $\mathrm{SE}$ \\
\hline A 253 & $18 \cdot 4$ & $0 \cdot 4$ & \multicolumn{2}{|c|}{ - } & 0.5 & $0 \cdot 3$ & $0 \cdot 2$ & $0 \cdot 3$ \\
\hline B 227 & $18 \cdot 0$ & $0 \cdot 4$ & $0 \cdot 5$ & $0 \cdot 3$ & \multicolumn{2}{|c|}{ - } & 0.2 & $0 \cdot 3$ \\
\hline$A+B 480$ & $18 \cdot 2$ & $0 \cdot 3$ & $-0 \cdot 2$ & $0 \cdot 2$ & $0 \cdot 2$ & $0 \cdot 2$ & \multicolumn{2}{|c|}{-} \\
\hline
\end{tabular}

Table 5. Regression of body fat percentage (BF\%) as dependent variable, and body mass index (BMI), age and sex as independent variables in the populations of adults (age $\geqslant 16$ years)

(Means and their standard errors)

\begin{tabular}{|c|c|c|c|c|c|c|c|c|c|c|c|}
\hline \multirow[b]{3}{*}{ Group $n$} & \multicolumn{8}{|c|}{ Regression coefficients } & & & \\
\hline & \multicolumn{2}{|c|}{ BMI } & \multicolumn{2}{|c|}{ Sex* } & \multicolumn{2}{|c|}{ Age } & \multicolumn{2}{|c|}{ Intercept } & \multicolumn{2}{|c|}{ SEE } & \multirow[b]{2}{*}{$R^{2}$} \\
\hline & Mean & $\mathbf{S E}$ & Mean & $\mathbf{S E}$ & Mean & SE & Mean & $\mathrm{SE}$ & $\mathrm{BF} \%$ & $\mathrm{CV} \%$ & \\
\hline A 356 & $\begin{array}{l}+1.61 \\
+1.63 \\
+1.16\end{array}$ & $\begin{array}{l}0.10 \\
0.07 \\
0.06\end{array}$ & $\begin{array}{r}-\overline{-} \\
-9 \cdot 8 \\
-10.7\end{array}$ & $\begin{array}{l}0.6 \\
0.5\end{array}$ & +0.23 & 0.01 & $\begin{array}{r}-12.1 \\
-8.9 \\
-5.0\end{array}$ & $\begin{array}{l}2.4 \\
1.8 \\
1.4\end{array}$ & $\begin{array}{l}7 \cdot 2 \\
5 \cdot 4 \\
4 \cdot 2\end{array}$ & $\begin{array}{l}29 \\
22 \\
17\end{array}$ & $\begin{array}{l}0.40 \\
0.67 \\
0.80\end{array}$ \\
\hline В 393 & $\begin{array}{l}+1.45 \\
+1.63 \\
+1.22\end{array}$ & $\begin{array}{l}0 \cdot 09 \\
0 \cdot 07 \\
0 \cdot 06\end{array}$ & $\begin{array}{r}-10.0 \\
-10.9\end{array}$ & $\begin{array}{l}0.5 \\
0.4\end{array}$ & +0.22 & 0.01 & $\begin{array}{l}-8 \cdot 1 \\
-8 \cdot 3 \\
-5 \cdot 6\end{array}$ & $\begin{array}{l}2.3 \\
1.7 \\
1.3\end{array}$ & $\begin{array}{l}7 \cdot 0 \\
5 \cdot 1 \\
4 \cdot 0\end{array}$ & $\begin{array}{l}27 \\
20 \\
16\end{array}$ & $\begin{array}{l}0.36 \\
0.66 \\
0.80\end{array}$ \\
\hline$A+B 747$ & $\begin{array}{l}+1.53 \\
+1.63 \\
+1.20\end{array}$ & $\begin{array}{l}0 \cdot 07 \\
0 \cdot 05 \\
0 \cdot 04\end{array}$ & $\begin{array}{r}-9.9 \\
-10.8\end{array}$ & $\begin{array}{l}0.4 \\
0.3\end{array}$ & +0.23 & 0.01 & $\begin{array}{r}-10.1 \\
-8.6 \\
-5.4\end{array}$ & $\begin{array}{l}1.6 \\
1.2 \\
1.0\end{array}$ & $\begin{array}{l}7 \cdot 1 \\
5 \cdot 2 \\
4 \cdot 1\end{array}$ & $\begin{array}{l}28 \\
21 \\
16\end{array}$ & $\begin{array}{l}0.38 \\
0.67 \\
0.79\end{array}$ \\
\hline
\end{tabular}

SEE, standard error of estimate; CV\%, coefficient of variation; $R^{2}$ explained variance.

* Sex: males $=1$, females $=0$.

categories: a population of children (age $\leqslant 15$ years) and a population of adults (age $\geqslant$ 16 years). Table 2 shows some physical characteristics of the subjects in the validation and cross-validation sample in children and adults. Neither the two groups of children, nor the two groups of adults differed significantly in physical characteristics. Although the BMI distribution was slightly skewed, log transformation did not improve the fit of the regression equations.

In group $\mathrm{A}$ of the population of children the relationship between $\mathrm{BF} \%$ as dependent variable and BMI, age and sex as independent variables was analysed. Table 3 shows the stepwise multiple regression model. The prediction formula was validated in group $\mathrm{B}$ of the population of children. The difference between observed $\mathrm{BF} \%$ and predicted $\mathrm{BF} \%$ was not significant (Table 4). Also in group B of the population of children the relationship between $\mathrm{BF} \%$ as dependent variable and BMI, age and sex as independent variables was analysed. 
Table 6. Observed body fat percentage (BF\%) and difference with predicted $B F \%$ in the two populations of adults and the two combined populations of adults $\dagger$

(Means with their standard errors)

\begin{tabular}{|c|c|c|c|c|c|c|c|c|}
\hline \multirow[b]{3}{*}{ Group $n$} & & & \multicolumn{6}{|c|}{$\begin{array}{l}\text { Difference between predicted and } \\
\text { observed BF } \% \text { when predicted with } \\
\text { equation from population } \ddagger\end{array}$} \\
\hline & \multicolumn{2}{|c|}{ Observed $\mathrm{BF} \%$} & \multicolumn{2}{|c|}{ A } & \multicolumn{2}{|l|}{ B } & \multicolumn{2}{|c|}{$A+B$} \\
\hline & Mean & $\mathrm{SE}$ & Mean & $\mathrm{SE}$ & Mean & $\mathbf{S E}$ & Mean & $\mathrm{SE}$ \\
\hline A 356 & $24 \cdot 6$ & 0.5 & - & & $-0.5^{*}$ & $0 \cdot 2$ & $-0 \cdot 3$ & 0.2 \\
\hline B 393 & $25 \cdot 7$ & 0.4 & $0.5^{*}$ & 0.2 & - & & 0.2 & 0.2 \\
\hline$A+B 747$ & $25 \cdot 2$ & $0 \cdot 3$ & $0 \cdot 3$ & $0 \cdot 2$ & $-0 \cdot 2$ & $0 \cdot 2$ & - & \\
\hline
\end{tabular}

Table 7. Observed body fat percentage (BF\%) and difference with predicted $B F \%$ in several age groups

(Means with their standard errors)

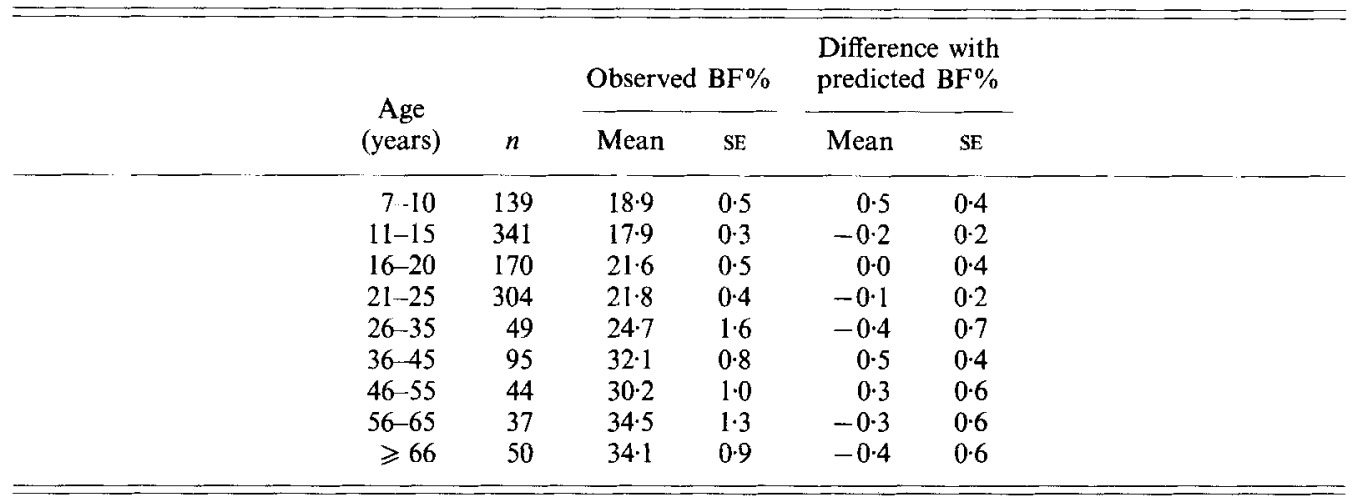

Table 3 also shows the results of this stepwise multiple regression analysis. The prediction formula obtained was validated in group A of the population of children. The difference between observed and predicted $\mathrm{BF} \%$ was not significant (Table 4). Therefore the two groups $\mathrm{A}$ and $\mathrm{B}$ within the population of children were combined and the relationship analysed again. Table 3 also gives the predicted formula based on the total population of children. In the combined population of children, age showed a slightly but statistically significant interaction with BMI $(P<0.05)$, indicating a statistically different relationship between $B F \%$ and $B M I$ at different ages. Taking this interaction into account in the regression analysis, the $R^{2}$ increased only from 0.38 to 0.39 , and the SE of the estimate (SEE) of the prediction decreased only by $0.03 \%$. For convenience the prediction formula $\mathrm{BF} \%=1.51 \times \mathrm{BMI}-0.70 \times$ age $-3.6 \times \operatorname{sex}+1.4$ (Table 3 ), without the interaction term, was used in subsequent analysis.

For the population of adults the same analyses were performed, that is, development of a prediction formula in group A, which was validated in group B and vice versa. Table 5 
Table 8. Observed body fat percentage (BF\%) and difference with predicted $B F \%$ in different body mass index (BMI) categories

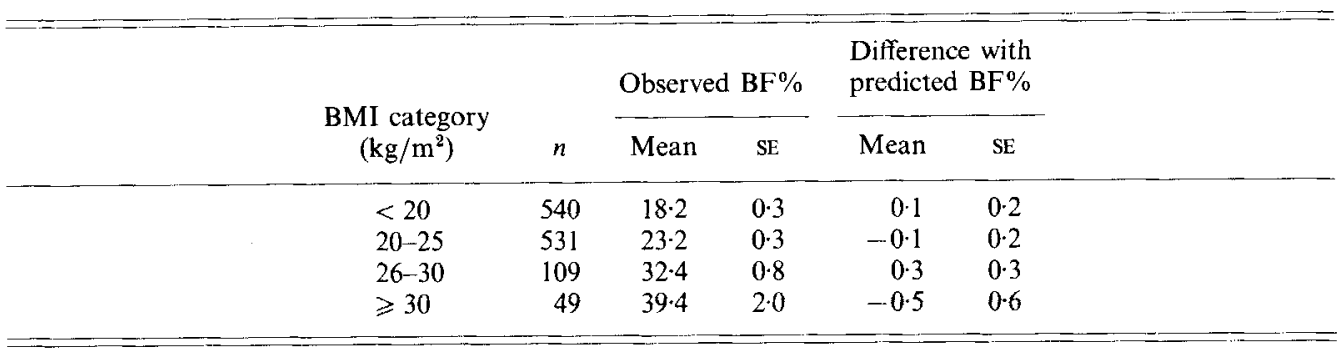

Table 9. External validation of the prediction formulas in different populations from the literature*

(Means with their standard errors)

\begin{tabular}{|c|c|c|c|c|c|}
\hline \multirow{2}{*}{$\begin{array}{c}\text { Age (years) } \\
\text { Mean }\end{array}$} & \multirow[b]{2}{*}{ Sex } & \multicolumn{2}{|c|}{ Reported BF\% } & \multirow{2}{*}{$\begin{array}{l}\text { Predicted } \\
\text { BF\% }\end{array}$} & \multirow[b]{2}{*}{ Reference } \\
\hline & & Mean & $\mathrm{SE}$ & & \\
\hline 10 & o & $19 \cdot 0$ & $1 \cdot 1$ & $18 \cdot 0$ & Slaughter et al. (1988) \\
\hline 10 & 吊 & $23 \cdot 0$ & $1 \cdot 7$ & $20 \cdot 9$ & Slaughter et al. (1988) \\
\hline 12 & d & $17 \cdot 0$ & $1 \cdot 3$ & 17.8 & Slaughter et al. (1988) \\
\hline 12 & q & $24 \cdot 0$ & $1 \cdot 3$ & $22 \cdot 6$ & Slaughter et al. (1988) \\
\hline 15 & $\partial$ & $14 \cdot 0$ & $0 \cdot 8$ & $13 \cdot 3$ & Slaughter et al. (1988) \\
\hline 15 & q & $24 \cdot 0$ & $1 \cdot 0$ & $22 \cdot 2$ & Slaughter et al. (1988) \\
\hline 22 & $\hat{\sigma}$ & 160 & $1 \cdot 2$ & $17 \cdot 6$ & Slaughter et al. (1988) \\
\hline 22 & q & 260 & $1 \cdot 1$ & $26 \cdot 6$ & Slaughter et al. (1988) \\
\hline 34 & d & $17 \cdot 7$ & 0.3 & $19 \cdot 2$ & Segal et al. (1988) \\
\hline 24 & q & $20 \cdot 6$ & $0 \cdot 4$ & $18 \cdot 7$ & Segal et al. (1988) \\
\hline $50-72$ & $\hat{\sigma}$ & 28 & 1.7 & $30 \cdot 3$ & Durnin \& Womersley (1974) \\
\hline $50-72$ & q & 39 & $1 \cdot 3$ & $40 \cdot 0$ & Durnin \& Womersley (1974) \\
\hline 25 & 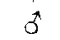 & $29 \cdot 6 \dagger$ & & $30 \cdot 3$ & Gray et al. (1989) \\
\hline 62 & 9 & $42 \cdot 8 \dagger$ & & $43 \cdot 7$ & Gray et al. (1989) \\
\hline
\end{tabular}

* For the ages $\leqslant 15$ years the prediction formula from Table 4 was used, for the ages $\geqslant 16$ years the prediction formula was from Table 6 .

$\dagger$ Only the mean value is given by the authors.

shows the stepwise multiple regression analysis performed in groups A and B, and Table 6 gives the cross-validation results. Although in the population of adults the differences between observed $\mathrm{BF} \%$ and predicted $\mathrm{BF} \%$ were sometimes statistically significant $(P<$ 0.05 ), they were very small (less than $0.5 \%$ ). Therefore, the values for the two groups of adults were also combined. Table 5 also gives the prediction formula for the total population of adults. In the population of adults, sex $(P<0.001)$ and age $(P<0.05)$ slightly interacted with BMI, but taking both interactions into account the $R^{2}$ only increased from 0.79 to 0.80 , and the SEE decreased only from 4.06 to $4.03 \%$. For reasons of convenience the prediction formula without interaction terms $(\mathrm{BF} \%=1.20 \times \mathrm{BMI}$ $-10 \cdot 8 \times \operatorname{sex}+0 \cdot 23 \times$ age $-5 \cdot 4$, Table 5 ) was used in subsequent analysis.

Table 7 shows the observed $\mathrm{BF} \%$ and the difference between observed and predicted $\mathrm{BF} \%$ in several age groups. The predicted $\mathrm{BF} \%$ did not differ significantly from the observed $\mathrm{BF} \%$ in all age groups. Also when comparing observed and predicted $\mathrm{BF} \%$ in males and females in different age groups, no differences were observed (results not shown). 
Table 8 shows the validity of the predicted $B F \%$ in groups of different apparent body fatness, based on the BMI. The BF\% in obese subjects (BMI $>30 \mathrm{~kg} / \mathrm{m}^{2}$ ) was slightly overestimated by the prediction formulas. This difference became statistically significant in obese subjects with a $\mathrm{BMI} \geqslant 33 \mathrm{~kg} / \mathrm{m}^{2}(n 19, \Delta \mathrm{BF} \%=-1.9($ SE 0.8$), P<0.05)$.

In Table 9 the observed $\mathrm{BF} \%$ and the predicted $\mathrm{BF} \%$ using the final prediction equations from Table 3 and Table 5 for children and adults respectively are given for some populations described in the literature. The mean differences were in general less than $2 \%$ $\mathrm{BF} \%$, and the predicted value was always within the $95 \%$ confidence interval of the observed value.

\section{DISCUSSION}

When using a weight-height index to assess body fat, it is necessary that this index has a high correlation with $\mathrm{BF} \%$, but also that this index is not correlated with body height (Keys et al. 1972), unless one assumes that body height and $\mathrm{BF} \%$ are correlated (Garrow \& Webster, 1985). These two criteria hold in general for the Quetelet index or BMI more than for other weight-height indices (Keys et al. 1972; Norgan \& Ferro-Luzzi, 1982). However, in children from about 7 years onwards, the BMI is positively related with age (Rolland-Cachera et al. 1982). In those children the increase in body-weight is faster compared with the increase in body height, and the BMI is theoretically positively correlated with body height. This was also observed in the present study. After the age of 16 years the positive correlation of the BMI with body height disappeared and became even slightly, but significantly negative.

In growing prepubertal children the $\mathrm{BF} \%$ generally remains fairly constant and slightly increases only in pubertal girls (Forbes, 1987; Deurenberg et al. 1990), whereas the BMI increases during this period. It can be questioned therefore, whether the BMI is a suitable predictor for $\mathrm{BF} \%$ in children under the age of 16 years. Therefore, the relationship between $\mathrm{BF} \%$ and $\mathrm{BMI}$ was analysed separately for children and adults, i.e. for subjects aged $\leqslant 15$ years and subjects aged $\geqslant 16$ years.

The negative correlation of the BMI with body height in adults was shown to be a negative correlation with $\mathrm{BF} \%$ and was also found in some other studies (Womersley \& Durnin, 1977; Sonsbeek 1985). However Keys et al. (1972) and Norgan \& Ferro-Luzzi (1982) generally found no correlation between BMI and body height. This disagreement between studies could be due to differences in age of the subjects studied. Both in the present study and in the study of Womersley \& Durnin (1977), this negative correlation was more pronounced in the older age groups. The correlation between $\mathrm{BF} \%$ and body height shows that the statement that a weight-height index as a measure of body fat has to be independent of height, is not necessarily true, as also indicated by Garrow \& Webster (1985).

In a population of children the explained variance of the regression model was rather low $(0 \cdot 38-0 \cdot 42$, Table 3$)$ compared with that of adults $(0 \cdot 79-0.80$, Table 5). Although the absolute prediction error (SEE) seemed comparable in children and adults, it was remarkably larger in children $(24 \% \mathrm{v} .16 \%$, expressed as percentage of variation, Tables 3 and 5). For this reason it may be questioned whether the BMI is a valid determinant for $\mathrm{BF} \%$ in children.

Both in the population of children and in the population of adults the prediction formulas obtained in the validation sample $\mathrm{A}$ predicted the $\mathrm{BF} \%$ in the cross-validation sample B quite well, and vice versa (Tables 4 and 6). Consequently, the prediction formulas based on the total population of children and adults were used in further calculations.

The explained variances of the final regression models were, at least in the population of adults, rather high, but, more importantly, the prediction error (SEE) in $\mathrm{BF} \%$ was rather 
low. There were significant interactions between BMI and age in children, and between $\mathrm{BMI}$ and age and sex in adults, indicating that the relationship between $\mathrm{BF} \%$ and $\mathrm{BMI}$ was not identical at all ages, and statistically different between sexes in adults. These effects, however, had only a small impact on the prediction of the $\mathrm{BF} \%$, and were neglected.

The slight overestimation of the $\mathrm{BF} \%$ in the obese subjects may be explained by the fact that the relationship between $\mathrm{BF} \%$ and $\mathrm{BMI}$ is theoretically asymptotic at higher values of BMI. However, using $\mathrm{BMI}^{2}$ or $\log \mathrm{BMI}$ instead of BMI did not improve the percentage explained variance and hence the accuracy of prediction (results not shown).

Validation of the prediction formulas in populations described in the literature, showed predicted $\mathrm{BF} \%$ values close to the observed values. They were always within the $95 \%$ confidence interval of the reported value, indicating that the prediction formulas also have a high external validity.

In the prediction formula obtained for the children, sex effects were less pronounced than in adults. This demonstrates the fact that in children the differences in body composition between the sexes are small compared with adults (Forbes, 1987). Another difference between the prediction formulas for children and adults is that the regression coefficient for age was positive in children, and negative in adults. This means that, even when bodyweight (and thus BMI) is constant in adults, the amount of body fat increases with age. This is in accordance with the fact that the relative amount of fat-free mass (i.e. muscle mass) decreases with advancing age (Forbes, 1987). In children the negative effect of age on the predicted $\mathrm{BF} \%$ is the consequence of the height-related increase in $\mathrm{BMI}$, due to the unproportional increases in weight and height.

The SEE values from the prediction equations in the present study are comparable with those found in other studies in which the relationship between $\mathrm{BF} \%$ and $\mathrm{BMI}$ was studied, as in males only (Norgan \& Ferro-Luzzi, 1982) or in groups of subjects with a smaller age range (Womersley \& Durnin, 1977; Deurenberg et al. 1989 a).

Garrow \& Webster (1985) found that the BMI was better correlated with body fat mass $(\mathrm{kg})$ compared with $\mathrm{BF} \%$. Also in this population, fat mass divided by height squared $\left(\mathrm{FM} / \mathrm{H}^{2}\right)$ correlated more strongly $\left(R^{2}=0.89\right)$ with $\mathrm{BMI}$ than did $\mathrm{BF} \%$, after taking age and sex into account. However, the sEe, expressed as coefficient of variation, was only marginally lower $(15.9 \%$ compared with $16.2 \%)$. It seems more convenient, therefore, to use the BMI as a measure of $\mathrm{BF} \%$ and not of fat mass $(\mathrm{kg})$.

The prediction error in the estimated $\mathrm{BF} \%$ using formulas based on the $\mathrm{BMI}$ is comparable with the prediction error when using formulas based on skinfold thickness measurements (Durnin \& Womersley, 1974; Pollock et al. 1975; Jackson \& Pollock, 1978; Slaughter et al. 1988; Deurenberg et al. 1990), for which in general a SEE of 3-5\% BF\% is reported. A prediction error of about $3-5 \% \mathrm{BF} \%$ has also been found in studies using the bioelectrical impedance technique (Lukaski et al. 1986; Jackson et al. 1988; Segal et al. 1988; Guo et al. 1989; Houtkoper et al. 1989).

The estimation of the BF\% from BMI is less dependent on intra- and inter-observer errors than skinfold measurements. Body-weight and body height are relatively easy to measure, but a well-trained observer is necessary for the measurement of skinfold thicknesses. Body impedance has to be measured under strictly standardized conditions to obtain reproducible results (Caton et al. 1988; Deurenberg et al. 1988) and is largely determined by the impedance of the extremities (Baumgartner et al. 1989; Fuller \& Elia, 1989), thus any inaccurate placement of the electrodes will cause relatively large errors. Well-trained observers are also necessary when using this method.

In summary, the assessment of $\mathrm{BF} \%$ from $\mathrm{BMI}$, sex and age provides accurate estimates of body composition. The use of different prediction formulas for children and adults is necessary. Prediction is more accurate for adults than children. The method is inexpensive 
and does not rely on well-trained observers, whereas the prediction error is comparable with other methods such as skinfold thickness measurements or bioelectrical impedance.

\section{REFERENCES}

Baumgartner, R. N., Chumlea, W. C. \& Roche, A. F. (1989). Estimation of body composition from bioelectrical impedance of body segments. American Journal of Clinical Nutrition 50, 221-226.

Caton, J. R., Molé, P. A., Adams, W. C. \& Heustis, D. S. (1988). Body composition analysis by bioelectrical impedance: effect of skin temperature. Medical Sciences in Sports and Exercise 20, 489-49I.

Conway, J. M., Norris, K. H. \& Bodwell, C. E. (1984). A new approach for the estimation of body composition by infrared interactance. American Journal of Clinical Nutrition 40, 1123-1130.

Deurenberg, P., Leenen, R., van der Kooy, K. \& Hautvast, J. G. A. J. (1989 c). In obese subjects the body fat percentage calculated with Siri's formula is an overestimation. European Journal of Clinical Nutrition $\mathbf{4 3}$, $569-575$.

Deurenberg, P., Pieters, J. J. L. \& Hautvast, J. G. A. J. (1990). The assessment of the body fat percentage by skinfold thickness measurements in childhood and young adolescence. British Journal of Nutrition 63, 293-303.

Deurenberg, P., van der Kooy, K., Hulshof, T. \& Evers, P. (1989a). Body mass index as a measure of body fatness in the elderly. European Journal of Clinical Nutrition 43, 231-236.

Deurenberg, P., Weststrate, J. A., Paymans, I. \& van der Kooy, K. (1988). Factors affecting bioelectrical impedance measurements in humans. European Journal of Clinical Nutrition 42, 1017-1022.

Deurenberg, P., Weststrate, J. A. \& van der Kooy, K. (1989 b). Is an adaptation of Siri's formula for the calculation of body fat percentage from body density in the elderiy necessary? European Journal of Clinical Nutrition 43, $559-567$.

Durnin, J. V. G. A. \& Womersley, J. (1974). Body fat assessed from total body density and its estimation from skinfold thickness, measurements on 481 men and women aged from 16 to 72 years. British Journal of Nutrition 32, 77-97.

Elia, M., Parkinson, S. A. \& Diaz, E. (1990). Assessment of body composition: near infra-red interactance. Proceedings of the Nutrition Society 49, 197A.

Forbes, G. B. (1987). Human Body Composition. New York: Springer Verlag.

Fuller, N. J. \& Elia, M. (1989). Potential use of bioelectrical impedance of the whole body and of body segments for the assessment of body composition, comparison with densitometry and anthropometry. European Journal of Clinical Nutrition 43, 779-792.

Garrow, J. S. \& Webster, J. (1985). Quetelet's index $\left(\mathrm{W} / \mathrm{H}^{2}\right)$ as a measure of fatness. International Journal of Obesity 9, 147-153.

Gray, D. S., Bray, G. A., Gemayel, N. \& Kaplan, K. (1989). Effect of obesity on bioelectrical impedance. American Journal of Clinical Nutrition 50, 255260.

Guo, S., Roche, A. F. \& Houtkoper, L. B. (1989). Fat free mass in children and young adults predicted from bioelectrical impedance and anthropometric variables. American Journal of Clinical Nutrition 50, 435-443.

Houtkoper, L. B., Lohman, T. G., Going, S. B. \& Hall, M. C. (1989). Validity of bioelectrical impedance for body composition assessment in children. Journal of Applied Physiology 66, 814-821.

Jackson, A. S. \& Pollock, M. L. (1978). Generalized equations for predicting body density of men. British Journal of Nutrition 40, 497-504.

Jackson, A. S., Pollock, M. L., Graves, J. \& Mahar, M. (1988). Reliability and validity of bioelectrical impedance in determining body composition. Journal of Applied Physiology 64, 529-534.

Keys, A, Fidanza, F., Karvonen, M. J., Kimura, N. \& Taylor, H. L. (1972). Indices of relative weight and obesity. Journal of Chronic Diseases 25, 329-343.

Khosla, T. \& Lowe, C. R. (1967). Indices of obesily derived from body weight and height. British Journal of Preventive and Social Medicine 21, 122-128.

Kleinbaum, D. G. \& Kupper, L. L. (1978). Applied Regression Analysis and Other Multivariable Methods. North Scituate, Massachusetts: Duxbury Press.

Lukaski, H. C. (1987). Methods for the assessment of body composition, traditional and new. American Journal of Clinical Nutrition 46, 437-456.

Lukaski, H. C., Bolonchuck, W. W., Hail, C. B. \& Siders, W. A. (1986). Validation of tetrapolar bioelectrical impedance method to assess human body composition. Journal of Applied Physiology 60, 1327-1332.

Lukaski, H. C., Johnson, P. E., Bolonchuck, W. W. \& Lykken, G. E. (1985). Assessment of fat free mass using bio-electrical impedance measurements of the human body. American Journal of Clinical Nutrition 41, 810-817.

Norgan, N. G. \& Ferro-Luzzi, A. (1982). Weight-height indices as estimates of fatness in men. Human Nutrition. Clinical Nutrition 36C, 363-372.

Pollock, M. L., Laughridge, E. E., Coleman, B., Linnerud, A. C. \& Jackson, A. (1975). Prediction of body density in young and middle aged women. Journal of Applied Physiology 38, 745-749.

Quetclet, L. A. (1869). Physique Sociale, vol. 2, p. 92. Brussels: C. Muquard1.

Rolland-Cachera, M. F., Sempe, F., Guillod-Bataille, M. M., Patois, E., Pequignot-Guggenbuhl, F. \& Fautrat, W. (1982). Adiposity indices in children. American Journal of Clinical Nutrition 36, 178-184. 
Segal, K. R., van Loan, M., Fitzgerald, P. I., Hodgdon, J. A. \& van Itallie, T. B. (1988). Lean body mass estimated by bioelectrical impedance analysis, a four site cross validation study. American Journal of Clinical Nutrition 47 , $7-14$.

Siri, W. E. (1961). Body composition from fluid spaces and density, analysis of methods. In Techniques for Measuring Body Composition, pp. 223-244 [J. Brozek and A. Henschel, editors]. Washington, DC: National Academy of Sciences.

Slaughter, M. H., Lohman, T. G., Boileau, R. A., Horswill, C. A., Stillman, R. J., van Loan, M. D. \& Bemben, D. A. (1988). Skinfold equations for estimation of body fatness in children and youth. Human Biology 60, $709-723$

Sonsbeek, J. L. A. (1985). The Dutch by Height and Weight. (In Dutch.) Maandberichten Gezondheidsstatistiek $(C B S)$ 6, 5-18.

Statistical Package for Social Sciences/PC (1988). Base Manual + V2.0. Chicago, Illinois: SPSS Inc.

Weststrate, J. A. \& Deurenberg, P. (1989). Body composition in children, proposal for a method for calculating body fat percentage from total body density or skinfold-thickness measurements. American Journal of Clinical Nutrition 50, $1104-1115$.

Womersley, J. \& Durnin, J. V. G. A. (1977). A comparison of the skinfold method with extent of overweight and various weight-height-relationships in the assessment of obesity. British Journal of Nutrition 38, $271-284$. 